\title{
Prototypical Predicates Have Unmarked Phonology
}

\author{
Jennifer L. Smith \\ University of North Carolina, Chapel Hill
}

\section{Lexical categories, phonological privilege, and predicate prototypicality}

Recent work recognizes that lexical category can be relevant for phonology, because phonological processes and phonotactics are sometimes category-sensitive (Smith 1997, 2001; Myers 2000; Bobaljik 2008; see also Cohen 1964; Chomsky \& Halle 1968; Postal 1968; Kenstowicz \& Kisseberth 1977).

Moreover, there are strong cross-linguistic tendencies concerning the nature of phonological differences between categories. One such tendency is a hierarchy of phonological privilege (Smith 2011). Phonological privilege includes the ability to avoid neutralization and consequently to support a larger number of phonological contrasts (Beckman 1999). ${ }^{1}$ In optimality-theoretic terms, privilege reflects a comparatively high ranking for faithfulness constraints and a comparatively low ranking for markedness (well-formedness) constraints. Stated more generally, less phonological privilege for a given position or category means greater phonological unmarkedness for that position or category. The hierarchy of phonological privilege seen cross-linguistically in category-sensitive phonological patterns is $\mathrm{N}>\mathrm{A}>\mathrm{V}$ : nouns are most likely to be privileged, with adjectives next, and verbs being least privileged.

Evidence is also emerging for lexical-category subclass effects in phonology. For example, proper nouns resist a syncope process that affects common nouns in Jordanian Arabic (Jaber 2011); for this process, proper nouns are privileged compared to common nouns. Another example is Itzaj Maya, in which transitive verbs undergo a phonological process of vowel deglottalization in a particular segmental context, but intransitive verbs do not (Hofling 2000:14), indicating less privilege for transitive verbs than for intransitives.

I propose that such sub-category effects are evidence that the $\mathrm{N}>\mathrm{A}>\mathrm{V}$ hierarchy of phonological privilege is actually part of a potentially more finely-grained scale, which can be summarized as in (1):

$$
\text { prototypical designators (arguments) > prototypical predicates }
$$

This generalized scale subsumes the $\mathrm{N}>\mathrm{A}>\mathrm{V}$ scale, and furthermore predicts that we can find languages with phonological processes for which there are additional distinctions among lexical sub-categories, such as those in (2) or (3).

$$
\begin{aligned}
& \text { proper nouns }>\text { common nouns }>A>V \\
& N>A>\underline{\text { verbs } 1>\text { verbs } 2}
\end{aligned}
$$

In (3), the subclasses verbs 1 and verbs 2 stand for any subdivisions within the class of verbs that have to do with prototypicality as a predicate. For example, intransitive verbs, which take only one argument, are more similar to adjectives than transitive verbs are, so in that sense, transitive verbs are further down the

* Many thanks to Michelle Fullwood, Shigeru Miyagawa, Elliott Moreton, Katya Pertsova, Donca Steriade, Ayaka Sugawara, the P-side Research Group at UNC, and audiences at MIT and at Phonology 2013, for inspiring discussion and helpful comments (any remaining errors or inadequacies are entirely my own). Thanks also to Chris Wiesen of the Odum Institute at UNC-CH for statistical consultation, and to Tomonori Nagano for sharing his annotated machine-readable version of Jacobsen's (1992) verb-pairs list.

1 Another diagnostic of phonological privilege is the ability to undergo augmentation processes, that is, phonological processes that increase perceptual salience (Smith 2005).

(C) 2014 Jennifer L. Smith

Proceedings of Phonology 2013

Completed February 13, 2014 
hierarchy - more prototypical as predicates - than intransitive verbs. This predicts less phonological privilege, which is to say greater phonological unmarkedness, for transitives, precisely what is seen in the case of Itzaj Maya described above.

The general prediction made by this understanding of the hierarchy of phonological privilege is that any of the basic lexical categories can potentially have further subdivisions that differ in phonological privilege. Given any such subdivision, more-prototypical predicates should most often show less phonological privilege - greater unmarkedness - than less-prototypical predicates.

This paper presents a case study in support of this proposal. Namely, in Tokyo Japanese, unergative verbs (more-prototypical predicates) show greater phonological unmarkedness with respect to pitch accent than unaccusative verbs (less-prototypical predicates). Implications of this finding for our understanding of lexical-category effects in phonology are also considered.

\section{Case study: Unergativity and accentedness in Tokyo Japanese}

In Tokyo Japanese, a morpheme of any category may be accented or unaccented. Accent is realized as a sharp pitch fall, represented phonologically as a $/ \mathrm{H}^{*}+\mathrm{L} /$ tone sequence associated to the accented syllable (McCawley 1968; Poser 1984; Pierrehumbert \& Beckman 1988; Venditti 2005).

Lexical contrast between accented and unaccented verbs
(a) kakéru
'runs' (V)
(b) kakeru
'is lacking' (V)

Although accentedness is phonologically contrastive for all lexical categories, the unmarked state in Japanese is arguably accented. Kubozono (2008: 181) notes that the "vast majority of (native) verbs and adjectives are accented" in Tokyo Japanese. Moreover, in Fukuoka Japanese, all verbs and adjectives are obligatorily accented (except in certain deaccenting modal contexts; see Kubo (1989) for details).

According to the proposal in (1), there should be languages in which more-prototypical predicates show greater phonological unmarkedness even within one basic lexical category, such as verbs. Intransitive verbs can be subdivided on morphosyntactic grounds into unergative verbs like 'dance', whose single argument is a logical subject, and unaccusative verbs like 'sink', whose single argument is a logical object (Perlmutter 1978). Unergatives, being agentive, are more prototypically verb-like (less adjective-like) than unaccusatives. As argued above, being accented is the unmarked state in Tokyo Japanese. So, if unergativity affects accentedness, the prediction is that unergatives are more likely to be accented than unaccusatives.

This section examines a set of 332 Tokyo Japanese intransitive verbs compiled by Jacobsen (1992), ${ }^{2}$ classifying them according to accentedness ( $(2.1)$, unergativity $(\S 2.2)$, and derivational suffix ( $(2.3)$. A logistic regression analysis supports the proposal in (1): the odds of being accented are more than twice as high for the unergatives as for the unaccusatives in the study.

2.1 Accentedness in the intransitive-verb dataset Each of the 332 intransitive verbs in the dataset was classified for accentedness as follows. An accent dictionary was consulted - in most cases this was NHK (1985), but Masuda (1974) was used for six verbs that had no entry in NHK (1985). Verbs were labeled as accented if they were listed only with an accented form; this designation therefore represents the maximally phonologically unmarked option where accentedness is concerned. Verbs were labeled as unaccented if they were either listed only as unaccented, or listed with both accented and unaccented variants.

2 Jacobsen (1992) presents 354 intransitive/transitive verb pairs. From this original set of intransitive verbs, the following exclusions were made: 14 intransitives listed twice by Jacobsen (because they have two different transitive counterparts) were included here only once each; three intransitives for which accent information was not available in either dictionary (see below) were excluded; and five additional intransitives were excluded because their unergativity could not be determined (discussed further in $§ 2.3$ ). 
Accentedness in the verb dataset: Summary

\begin{tabular}{lrr}
$\begin{array}{l}\text { consistently unaccented } \\
\text { variably unaccented }\end{array}$ & $\begin{array}{r}\text { 24 } \\
\text { vaccented }\end{array}$ & 197 (5naccented \\
& acc.3\%) \\
\hline
\end{tabular}

2.2 Unergativity in the intransitive-verb dataset Each of the 332 intransitive verbs in the dataset was classified as unaccusative or unergative according to a syntactic diagnostic for unaccusativity proposed by Kishimoto (1996): the deverbal nominal construction, shown in (6).

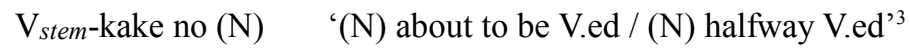

According to Kishimoto, unaccusative intransitive verbs can occur in the $\mathrm{V}_{\text {stem }}$ slot in this construction, but unergatives cannot. This construction was therefore used to classify each of the 337 intransitive verbs in the study as unaccusative or unergative. A Google search was performed for each intransitive verb in the string "Vstem-kake no," in Japanese orthography and enclosed in quotation marks.

Japanese verb orthography usually consists of a logograph that represents the verb root, plus syllabary graphemes to spell out derivational and inflectional affixes. However, any verb can in principle be written entirely in syllabary graphemes, and some verbs are often written this way, especially if the logograph for the root in question is rare. For this analysis, the choice between logograph and syllabary-only orthography for each verb was generally based on Nagano's (2011) annotation of Jacobsen's (1992) verb list. In a few cases, Nagano (2011) gives a syllabary-only form that is consistent with more than one homophonous verb; such verbs were converted to logographs in this analysis to allow for disambiguation.

As mentioned in footnote 2 above, five intransitive verbs listed in Jacobsen (1992) were excluded from the unergativity analysis because their status as unaccusatives or unergatives could not be tested using this method. First, the homographs yogore- 'become dirty, corrupted' and kegare- 'become unclean, polluted' (both written 污れ) were excluded, because it was not possible to confirm which verb is actually represented by this written form in Google search results (and searches using syllabary-only representations for these verbs had essentially no hits). Three other verbs were also excluded from the ergativity analysis. The verbs kom- 'become crowded' and kire- 'run out' were excluded because they occur as the second member in many V-V compounds and it was not possible to exclude those hits from the Google results. The verb mi'see', which Jacobsen (1992) included in his list as a sort of cross-reference for morphological reasons, was also excluded because it is not actually an intransitive verb.

For the remaining 332 verbs in the dataset, the $V_{\text {stem-kake no Google search results were interpreted as }}$

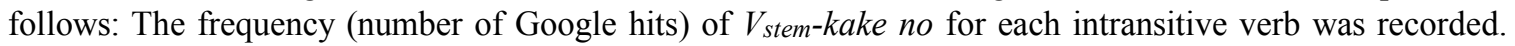
The logarithm of each frequency was then computed, because frequency effects in language typically depend on $\log$ frequencies rather than raw frequency values (Shapiro 1969; Carroll 1970).

log Google hits for 'V-kake.no'

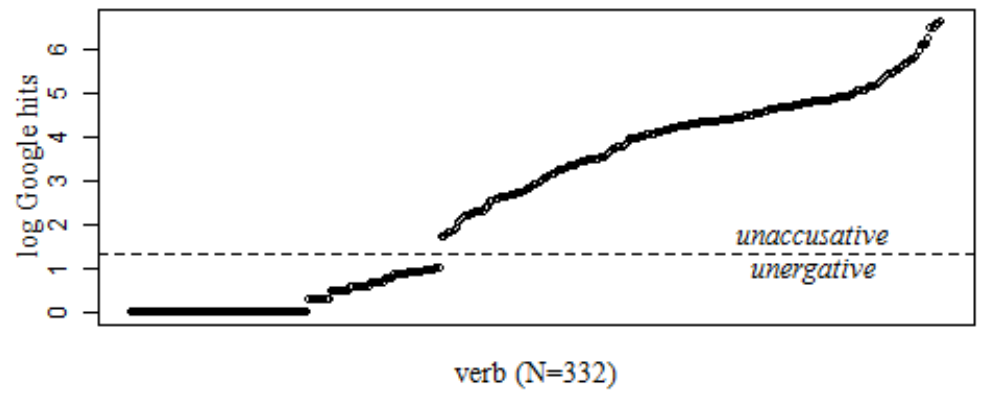

3 Which of the two interpretations the construction receives will depend on the lexical aspect class of the verb. 
As seen in (7), the log-frequency values fall into two clusters, one below 1.0 and another above 1.7. Verbs

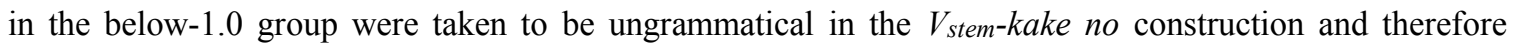
unergative, while verbs in the above-1.7 group were taken to be grammatical in the $V_{\text {stem-kake no }}$ construction and therefore unaccusative.

As with any use of Google search data for linguistic analysis, it is likely that a small number of the verbs have been wrongly classified here. For example, it may be the case that a few verbs that are in fact grammatical in this construction happen not to be attested in the search results (are accidental gaps), or a few verbs that are actually ungrammatical in this construction might appear in the search results, either because of errors in the Japanese text on web pages or because some particular search string occurs grammatically with a different interpretation than the one that was intended here. Still, to anticipate the results discussed in $\$ 2.4$, unergativity turns out to be a significant predictor of accentedness. The fact that there is a statistical effect indicates that the unergativity results are not too badly disrupted by errors in the Google data.

\begin{tabular}{lcc}
\multicolumn{3}{l}{ Unergativity in the verb dataset: Summary } \\
\hline unaccusative & 205 & $(61.7 \%)$ \\
unergative & 127 & $(38.3 \%)$
\end{tabular}

2.3 Derivational suffixes in the intransitive-verb dataset The intransitive verbs in this dataset all have a related transitive counterpart, a form that is sometimes called a lexical causative (Miyagawa 1984; Jacobsen 1992). In these intransitive/transitive verb pairs, the members of the pair are distinguished by some sort of "derivational suffix" on one or both verb stems. Some bound morphemes in Japanese affect the accentedness status of the stems that they form (McCawley 1968). Therefore, as part of an analysis of the effect of unergativity on accentedness, it is important to control for the possibility that derivational suffixes are affecting accentedness in intransitive verbs.

Examples of intransitive/transitive verb pairs from Jacobsen (1992) are shown in (9).

Intransitive/transitive verb pairs and suffix patterns in Tokyo Japanese: examples

\begin{tabular}{|c|c|c|c|c|c|c|}
\hline \multicolumn{3}{|c|}{ intransitive } & \multicolumn{2}{|l|}{ transitive } & \multicolumn{2}{|c|}{ \# of pairs in Jacobsen (1992) } \\
\hline (a) & ak-Ø- & '__opens' & ak-e- & 'open __' & 44 & $-\varnothing-/-\mathrm{e}-$ \\
\hline (b) & jak-e- & '__ burns' & jak-Ø & 'burn __' & 30 & $-\mathrm{e}-/-\varnothing-$ \\
\hline (c) & káe-r- & '_ returns' & káe-s- & 'return __' & 27 & $-r-/-s-$ \\
\hline (d) & nukum-ár- & '_ warms up' & nukum-é- & 'warm__up' & 70 & $-a r-/-e^{-4}$ \\
\hline
\end{tabular}

As (9) demonstrates, the morphology that relates the two verb stems in these pairs is not straightforward. These so-called derivational suffixes are not fully productive, although many of them recur in multiple intransitive/transitive pairs-Jacobsen (1992) identifies 15 suffix patterns that occur in at least two verb pairs, including the four patterns exemplified in (9), which are among the most robustly attested in Jacobsen's verb-pair list. The suffixes are also largely arbitrary, as seen in the "reverse" pairs in (9)(a-b), where the suffix $-e$ - appears in the transitive and the intransitive stem respectively (although there is also some systematicity; notably, suffixes that include an $/ \mathrm{r} /$ generally occur in intransitives and suffixes that include an /s/ generally occur in transitives, which is reminiscent of the productive passive and causative suffixes, -(r)are- and -(s)ase- respectively). The precise morphological status of these suffixes is therefore controversial. In any case, the label "derivational suffix" is used here for convenience and is not intended to represent any specific theoretical claims.

4 The fact that the pitch accent is marked on vowels belonging to the suffix in the verbs in (9)(d) does not presuppose or entail that the accent is phonologically affiliated with these suffixes. Accent placement in verbs is predictable based on the conjugation form (McCawley 1968); in all accented verbs in (9), the accent is marked on the location where it would appear in the nonpast (citation) form, which takes the inflectional suffix $-(r) u$. 
Each of the 332 verbs in the dataset was classified by its derivational suffix, as follows. For each verb pair presented by Jacobsen (1992), contiguous material shared by the intransitive and transitive stems was taken to belong to the base, and any further material in the intransitive stem (excluding the nonpast inflectional suffix $-(r) u$, which appears in citation forms) was classified as the derivational suffix.

Derivational suffixes in the verb dataset: Summary

\begin{tabular}{llllllllllllllllll}
\hline suffix & $\varnothing$ & $e$ & ar & $r$ & re & $i$ & are & or & $r i$ & $w$ & $i r$ & $k e$ & oe & ore & sar & sure & $u r$ \\
frequency & 96 & 80 & 76 & 31 & 16 & 14 & 5 & 3 & 2 & 2 & 1 & 1 & 1 & 1 & 1 & 1 & 1 \\
\hline
\end{tabular}

2.4 Results: Effect of unergativity on accentedness Statistical analyses were performed to determine whether unergativity has an effect on accentedness. First, a chi-square analysis confirms that there is a significant association between unergativity and accentedness.

(11) Chi-square analysis: unergativity and accentedness

\begin{tabular}{l|ll}
$\chi^{2}(1, \mathrm{~N}=332)=$ & $5.44, p=0.020$ \\
& unaccusative & unergative \\
\hline unaccented & 94 & 41 \\
accented & 111 & $\mathbf{8 6}$ \\
& $54.15 \%$ accented & $67.71 \%$ accented
\end{tabular}

A logistic regression analysis (Jaeger 2008; UCLA 2013) was also performed, to determine whether accentedness (yes or no) is predicted by unergativity (yes or no) or suffix (as listed in (10)). Detailed results are shown in (12); the reference category (intercept) contains the items that are unaccusative and have no overt derivational suffix.

(12) Summary of the ordinary logistic regression model

Log likelihood of the model: $-204.2509(d f=18)$

\begin{tabular}{llllll}
\hline Predictor & Coefficient & Std. Error & Wald $Z$ & $p$ & significance \\
\hline (Intercept) & -0.1344 & 0.2350 & -0.572 & 0.56749 & \\
unergative & $\mathbf{0 . 8 0 7 3}$ & $\mathbf{0 . 2 5 9 8}$ & $\mathbf{3 . 1 0 8}$ & $\mathbf{0 . 0 0 1 8 9}$ & $* *$ \\
suffix ar & -0.2582 & 0.3161 & -0.817 & 0.41414 & \\
suffix are & 0.3921 & 0.9485 & 0.413 & 0.67931 & \\
suffix $e$ & 0.4617 & 0.3185 & 1.449 & 0.14723 & \\
suffix $\boldsymbol{i}$ & $\mathbf{2 . 6 1 3 6}$ & $\mathbf{1 . 0 6 3 8}$ & $\mathbf{2 . 4 5 7}$ & $\mathbf{0 . 0 1 4 0 2}$ & $*$ \\
suffix ir & 16.7004 & 2399.5447 & 0.007 & 0.99445 & \\
suffix $k e$ & 15.8931 & 2399.5447 & 0.007 & 0.99472 & \\
suffix oe & -17.2390 & 2399.5447 & -0.007 & 0.99427 & \\
suffix or & 0.3113 & 1.2645 & 0.246 & 0.80558 & \\
suffix ore & -16.4317 & 2399.5447 & -0.007 & 0.99454 & \\
suffix $r$ & 0.2903 & 0.4277 & 0.679 & 0.49732 & \\
suffix re & $\mathbf{1 . 4 3 5 8}$ & $\mathbf{0 . 6 8 1 2}$ & $\mathbf{2 . 1 0 8}$ & $\mathbf{0 . 0 3 5 0 5}$ & $*$ \\
suffix $r i$ & -16.8547 & 1646.5853 & -0.010 & 0.99183 & \\
suffix sar & 15.8931 & 2399.5447 & 0.007 & 0.99472 & \\
suffix sure & -16.4317 & 2399.5447 & -0.007 & 0.99454 & \\
suffix ur & 15.8931 & 2399.5447 & 0.007 & 0.99472 & \\
suffix $w$ & 15.8931 & 1696.7344 & 0.009 & 0.99253 & \\
\hline
\end{tabular}

- Dispersion parameter for binomial family taken to be 1 
- Null deviance: 448.6 on $331 d f$

- Residual deviance: 408.5 on $314 d f$

- 5 observations deleted due to missingness [these were the verbs described as excluded in §2.2]

- AIC: 444.5

- Number of Fisher Scoring iterations: 15

- $\chi^{2}=40.10(17 d f), p<0.01$ : the model fits significantly better than an empty model

As (12) shows, unergativity is indeed a highly significant predictor of accentedness ( $p=0.00189$ ), even when the derivational suffixes are included in the statistical model. Specifically, being unergative increases the odds of a verb being accented by a factor of $2.24\left(e^{(0.8073)}=2.24\right)$. This result can be confirmed informally by visual inspection of the counts given in (11): unaccusatives are accented or unaccented in roughly equal proportions, but unergatives are just about twice as likely to be accented as unaccented. (The statistical results in (12) also show that two of the 16 suffixes $(-i-,-r e-)$ are significant predictors of accentedness $(p<0.05)$, but the other 14 are not. $)$

In summary, the unergative and unaccusative verb subclasses in Tokyo Japanese do pattern as predicted by predicate prototypicality. Unergatives, which are more-prototypical predicates, are significantly more likely to be accented, which is the phonologically unmarked property in this language.

\section{Discussion and implications}

The case study from Tokyo Japanese presented here supports the proposal that the hierarchy of phonological privilege seen in category-specific phonological phenomena, $\mathrm{N}>\mathrm{A}>\mathrm{V}$, can be understood more generally as a hierarchy from prototypical designators (or arguments) on the high-privilege end to prototypical predicates on the low-privilege end. This approach predicts additional phonological distinctions within $\mathrm{N}, \mathrm{A}, \mathrm{V}$ along factors related to prototypicality as a designator or as a predicate, such as the effect of unergativity on accentedness in Tokyo Japanese discussed here.

But why should prototypicality as a designator or as a predicate matter for phonological patterns at all? I propose that this factor influences category-specific phonology through circumstances that arise in language acquisition.

Lexical categories behave differently in language acquisition: there is evidence that nouns are acquired by children earlier and in greater numbers than verbs, even in typologically and culturally distinct languages (see reviews in Ogura et al. 2006; D'Odorico \& Fasolo 2007). In this context, it is worth noting that the hierarchy of phonological privilege proposed here, $\mathrm{N}>\ldots>\mathrm{V}$, converges with category hierarchies that have been proposed for morphosyntax (e.g., Ross 1972; Langacker 1987; Croft 1990). Hopper \& Thompson (1985) suggest that such hierarchies may have their origin in discourse effects. There is indeed evidence for semantic, discourse-related, or conceptual-salience differences among lexical categories, such as aphasia studies indicating that noun-related and verb-related abilities are dissociated (Rapp \& Caramazza 2002; Mätzig et al. 2009).

Moreover, viewing the phonological relevance of the lexical-category hierarchy as arising in acquisition may explain two of the typological patterns reported in Smith (2011). First, the basic hierarchy $\mathrm{N}>\mathrm{A}>\mathrm{V}$ is a very strong tendency in the typology of category-sensitive phonological effects, but not an absolute-it has exceptions, ${ }^{5}$ such as Ewe (Ansre 1961), in which verbs have greater possibilities for tonal contrast than nouns. Its status as a strong tendency rather than an absolute suggests that the hierarchy of phonological privilege is likely not an innate universal, but is something that is learned —or innovated during acquisition on the basis of asymmetries in the learning data or misperception on the part of the learner (Myers 2002; Blevins 2004). Second, lexical-category effects in phonology are partially parallel

5 Sugawara (in prep.) documents a very strong tendency for personal names to be accented in Tokyo Japanese, which, as argued in $\$ 2.1$ above, is the unmarked phonological pattern. This therefore looks like it might be a case where common nouns have more phonological privilege (more possibility for contrast) than proper nouns; if so, this case may be an exception to the predicate-prototypicality hierarchy, just as Ewe is with its unusual V $>\mathrm{N}$ pattern. As additional examples of phonological differences among lexical sub-categories are uncovered, the strength of the tendency for such cases to follow the hierarchy of predicate prototypicality can be more thoroughly examined. 
with (though not simply reducible to) other morphosyntactic differences between categories, such as the tendency for nouns to be free but verbs bound. This is potentially important because morphosyntactic differences between categories might lead learners to notice — or innovate — distinct phonological patterns in those categories.

A final point to note is that the lexical-category hierarchy of phonological privilege seems to take the shape of a markedness scale, a prominence-based scale that gives rise to structured sets of constraints. Analogues in phonology include sonority (Prince \& Smolensky 2004), place of articulation (Lombardi 2001), or affinity for nasalization (Walker 1998). Analogues in morphosyntax include animacy (Silverstein 1976), case (Keenan \& Comrie 1977), or definiteness (Croft 1988); see also Aissen (2003) for a review. Thus, there may be general insights into relationships between markedness scales and learning biases in acquisition that are to be gained from comparisons between lexical-category effects in phonology and other markedness scales.

\section{References}

Aissen, Judith. 2003. Differential object marking: Iconicity vs. economy. Natural Language and Linguistic Theory 21: 435-483.

Ansre, Gilbert. 1961. The tonal structure of Ewe. Hartford: Hartford Studies in Linguistics.

Beckman, Jill N. 1999. Positional faithfulness. New York: Garland.

Blevins, Juliette. 2004. Evolutionary Phonology: The emergence of sound patterns. Cambridge: Cambridge University Press.

Bobaljik, Jonathan David. 2008. Paradigms (Optimal and otherwise): A case for skepticism. In Asaf Bachrach \& Andrew Nevins (eds.), Inflectional Identity, 29-54. Oxford: Oxford University Press.

Carroll, John B. 1970. An alternative to Juilland's Usage Coefficient for lexical frequencies, and a proposal for a Standard Frequency Index (SFI). Computer Studies in the Humanities and Verbal Behavior 3: 61-65.

Chomsky, Noam \& Halle, Morris. 1968. The sound pattern of English. New York: Harper \& Row.

Cohen, Marcel. 1964. Catégories de mots et phonologie. In Carroll E. Reed (ed.), Études phonologiques dédiées à la mémoire de M. le Prince N. S. Trubetzkoy. (Reprint with new preface of Travaux du Cercle Linguistique de Prague 8, 1939), 36-42. University, Ala.: U. of Alabama Press.

Croft, William. 1988. Agreement vs. case marking and direct objects. In Michael Barlow \& Charles Ferguson (eds.), Agreement in natural language, 159-180. Stanford: CSLI.

Croft, William. 1990. A conceptual framework for grammatical categories. Journal of Semantics 7: 245-279.

D'Odorico, Laura, \& Mirco Fasolo. 2007. Nouns and verbs in the vocabulary acquisition of Italian children. Journal of Child Language 34: 891-907.

Hofling, Charles Andrew. 2000. Itzaj Maya grammar. Salt Lake City: University of Utah Press.

Hopper, Paul J., \& Sandra A. Thompson. 1985. The iconicity of the universal categories 'noun' and 'verb'. In John Haiman (ed.), Iconicity in syntax, 151-183. Amsterdam: John Benjamins.

Jaber, Aziz. 2011. High vowel syncope in Jordanian Arabic: A positional faithfulness treatment. Ms., UNC Chapel Hill.

Jacobsen, W. M. 1992. The transitive structure of events in Japanese. Tokyo: Kuroshio Publishers.

Jaeger, T. Florian. 2008. Categorical data analysis: Away from ANOVAs (transformation or not) and towards logit mixed models. Journal of Memory and Language 59: 434-446.

Keenan, Edward, \& Bernard Comrie. 1977. Noun phrase accessibility and universal grammar. Linguistic Inquiry 8: 6399.

Kenstowicz, Michael, \& Charles Kisseberth. 1977. Topics in phonological theory. New York: Academic Press.

Kishimoto, Hideki. 1996. Split intransitivity in Japanese and the Unaccusative Hypothesis. Language 72: 248-286.

Kubo, Tomoyuki. 1989. Hukuoka-si hougen no, dare $\cdot$ nani tou no gimonsi o hukumu bun no pitti pataan [The pitch patterns of sentences containing WH-words in the Fukuoka City dialect]. Kokugogaku 156: 1-12.

Kubozono, Haruo. 2008. Japanese accent. In Shigeru Miyagawa \& Mamoru Saito (eds.), The Oxford handbook of Japanese linguistics, 165-191. Oxford: Oxford University Press.

Langacker, Ronald W. 1987. Foundations of Cognitive Grammar, vol. 1. Stanford: Stanford University Press.

Lombardi, Linda. 2001. Why Place and Voice are different. In Linda Lombardi (ed.), Segmental phonology in Optimality Theory, 13-45. Cambridge: Cambridge University Press.

Masuda, Koh (ed.). 1974. Kenkyusha's new Japanese-English dictionary, 4ed. Tokyo: Kenkyusha.

Mätzig, Simone, Judit Druks, Jackie Masterson, \& Gabriella Vigliocco. 2009. Noun and verb differences in picture naming: Past studies and new evidence. Cortex 45: 738-758.

McCawley, John D. 1968. The phonological component of a grammar of Japanese. The Hague: Mouton.

Miyagawa, Shigeru. 1984. Blocking and Japanese causatives. Lingua 64: 177-207. 
Myers, Scott. 2000. Boundary disputes: The distinction between phonetic and phonological sound patterns. In Noel Burton-Roberts, Philip Carr, \& Gerard Docherty (eds.), Phonological knowledge: Conceptual and empirical issues, 245-272. Oxford: Oxford University Press.

Myers, Scott. 2002. Gaps in factorial typology: The case of voicing in consonant clusters. Ms., UT Austin.

Nagano, Tomonori. 2011. List of Jacobsen (1992) verb pairs with Japanese orthography. Accessed May 15, 2013, at $<$ http://faculty.lagcc.cuny.edu/tnagano/ELJResources/docs/ELJ103JapaneseTransitivePairSimplified.pdf $>$.

NHK. 1985. Nihongo hatuon akusento ziten [Japanese pronunciation and accent dictionary]. Tokyo: Nippon Hôsô Shuppan Kyôkai.

Ogura, Tamiko, Philip S. Dale, Yukie Yamashita, Toshiki Murase, \& Aki Mahieu. 2006. The use of nouns and verbs by Japanese children and their caregivers in book-reading and toy-playing contexts. Journal of Child Language 33: $1-29$.

Perlmutter, David M. 1978. Impersonal passives and the Unaccusative Hypothesis. Berkeley Linguistic Society 4: $157-$ 190.

Pierrehumbert, Janet B., \& Mary E. Beckman. 1988. Japanese tone structure. Cambridge, Mass.: MIT Press.

Poser, William J. 1984. The phonetics and phonology of tone and intonation in Japanese. Doctoral dissertation, MIT.

Postal, Paul M. 1968. Aspects of phonological theory. New York: Harper \& Row.

Prince, Alan, \& Paul Smolensky. 2004. Optimality Theory: Constraint interaction in generative grammar. Oxford: Blackwell.

Rapp, Brenda, \& Alfonso Caramazza. 2002. Selective difficulties with spoken nouns and written verbs: A single case study. Journal of Neurolinguistics 15: 373-402.

Ross, J. R. 1972. Endstation Hauptwort: The category squish. Chicago Linguistic Society 8: 316-339.

Shapiro, Bernard J. 1969. The subjective estimation of relative word frequency. Journal of Verbal Learning and Verbal Behavior 8: 248-251.

Silverstein, Michael. 1976. Hierarchy of features and ergativity. In R.M.W. Dixon (ed.), Grammatical categories in Australian languages, 112-171. Canberra: Australian Institute of Aboriginal Studies.

Smith, Jennifer L. 1997. Noun faithfulness: On the privileged behavior of nouns in phonology. Ms., University of Massachusetts, Amherst. <http://www.unc.edu/ jlsmith/home/pdf/nfaith97.pdf $>$.

Smith, Jennifer L. 2001. Lexical category and phonological contrast. In Robert Kirchner, Joe Pater, \& Wolf Wikely (eds.), Workshop on the lexicon in phonetics and phonology, 61-72. Edmonton: University of Alberta.

Smith, Jennifer L. 2005. Phonological augmentation in prominent positions. New York: Routledge.

Smith, Jennifer L. 2011. Category-specific effects. In Marc van Oostendorp, Colin Ewen, Beth Hume, \& Keren Rice (eds.), The Blackwell companion to phonology, 2439-2463. Malden, Mass.: Wiley-Blackwell.

Sugawara, Ayaka. (in prep.) Japanese accent is largely predictable: Evidence from given names. Ms., MIT.

UCLA Statistical Consulting Group. 2013. R data analysis examples: Logit regression. Accessed June 20, 2013, at $<\mathrm{http} / /$ www.ats.ucla.edu/stat/r/dae/logit.htm>.

Venditti, Jennifer J. 2005. The J_ToBI model of Japanese intonation. In Sun-Ah Jun (ed.), Prosodic typology: The phonology and intonation of phrasing, 172-200. Oxford: Oxford University Press.

Walker, Rachel. 1998. Nasalization, neutral segments, and opacity effects. Doctoral dissertation, UC Santa Cruz. 